\title{
Early stress evokes age-dependent biphasic changes in hippocampal neurogenesis, epigenetic regulation of the bdnf gene, and cognitive behavior
}

Vidita Vaidya

From International Conference on Human Genetics and 39th Annual Meeting of the Indian Society of Human Genetics (ISHG)

Ahmadabad, India. 23-25 January 2013

An experience of stress in early life is predominantly associated with negative consequences including increased anxiety and depressive behavior, as well as a failure to mount appropriate stress responses. It has remained a source of debate whether early stress also evokes potentially adaptive consequences that equip animals to cope better with their environment. We have shown that early stress exposure facilitates transient, adaptive changes in hippocampal neurogenesis, enhanced trophic factor expression and improved cognitive performance, thus providing possible competitive advantages in stressful environments. However, middle-aged animals with a history of early stress exhibit aladaptive effects on hippocampal neurogenesis, reduced trophic factor expression and impairments in cognitive performance. Our study provides novel insights into the short and long-term consequences of early stress, demonstrating biphasic, as well as unique, age-dependent changes at the molecular, epigenetic, neurogenic and behavioral level. These results compel a reappraisal of the traditional notion that early stress is deterministic for future negative outcomes. Our studies suggest that when observed across a life-span, early stress experience evokes both adaptive as well as maladaptive changes that emerge in a temporally regulated manner, with early adaptive outcomes that may eventually exert a high cost, evoking maladaptive consequences.

Published: 21 January 2014

Correspondence: vvaidya@tifr.res.in

Department of Biological Sciences, Tata Institute of Fundamental Research, Mumbai, India
doi:10.1186/1755-8166-7-S1-I38

Cite this article as: Vaidya: Early stress evokes age-dependent biphasic changes in hippocampal neurogenesis, epigenetic regulation of the bdnf gene, and cognitive behavior. Molecular Cytogenetics 2014 7(Suppl 1):138.
Submit your next manuscript to BioMed Central and take full advantage of:

- Convenient online submission

- Thorough peer review

- No space constraints or color figure charges

- Immediate publication on acceptance

- Inclusion in PubMed, CAS, Scopus and Google Scholar

- Research which is freely available for redistribution
() Biomed Central 